\title{
In vivo monitoring the biodegradation of magnesium alloys with an electrochemical $\mathrm{H}_{2}$ sensor
}

Daoli Zhao ${ }^{\text {a }}$, Tingting Wang ${ }^{\mathrm{a}}$, Julia Kuhlmann ${ }^{\mathrm{a}}$, Zhongyun Dong ${ }^{\mathrm{b}}$, Shuna Chen ${ }^{\mathrm{b}}$, Madhura Joshi $^{\text {c }}$, Pravahan Salunke ${ }^{\text {c }}$, Vesselin N. Shanov ${ }^{d}$, Daeho Hong ${ }^{\text {e }}$, Prashant N. Kumta ${ }^{\text {e,f, g }}$ and William R. Heineman ${ }^{\mathrm{a}, *}$

${ }^{a}$ Department of Chemistry, University of Cincinnati, Cincinnati, Ohio 45221, USA

${ }^{b}$ Department of Internal Medicine, University of Cincinnati, Cincinnati, Ohio 45267, USA

${ }^{c}$ Department of Mechanical and Materials Engineering, University of Cincinnati, Cincinnati, $O H, 45221$, USA

${ }^{d}$ Department of Biomedical, Chemical and Environmental Engineering, University of Cincinnati, Cincinnati, $O H, 45221$, USA

${ }^{e}$ Department of Bioengineering, University of Pittsburgh, Pittsburgh, PA, 15261, USA

${ }^{f}$ Department of Chemical and Petroleum Engineering, University of Pittsburgh, Pittsburgh, PA, 15261, USA

${ }^{g}$ Department of Mechanical Engineering and Materials Science, University of Pittsburgh, Pittsburgh, PA 15261, USA

* Corresponding author: Tel.: +1-513-556-9210; fax: +1-513-556-9329

E-mail address: William.Heineman@uc.edu 


\section{ABSTRACT}

Monitoring the biodegradation process of magnesium and its alloys in vivo is challenging. Currently, this process is monitored by micro-CT and $\mathrm{X}$-ray imaging in vivo, which require large and costly instrumentation. Here we report a simple and effective methodology to monitor the biodegradation process in vivo by sensing $\mathrm{H}_{2}$ transdermally above a magnesium sample implanted subcutaneously in a mouse. An electrochemical $\mathrm{H}_{2}$ microsensor was used to measure the biodegradation product $\mathrm{H}_{2}$ at the surface of the skin for two magnesium alloys (ZK40 and AZ31) and one high purity magnesium single crystal $(\mathrm{Mg} 8 \mathrm{H})$. The sensor was able to easily detect low levels of $\mathrm{H}_{2}(30$ to $400 \mu \mathrm{M})$ permeating through the skin with a response time of about $30 \mathrm{~s} . \mathrm{H}_{2}$ levels were correlated with the biodegradation rate as determined from weight loss measurements of the implants. This new method is noninvasive, fast and requires no major equipment.

\section{Statement of Significance}

Biomedical devices such as plates and screws used for broken bone repair are being developed out of biodegradable magnesium alloys that gradually dissolve when no longer needed. This avoids subsequent removal by surgery, which may be necessary if complications arise. A rapid, non-invasive means for monitoring the biodegradation process in vivo is needed for animal testing and point of care (POC) evaluation of patients. Here we report a novel, simple, fast, and noninvasive method to monitor the biodegradation of magnesium in vivo by measuring the biodegradation product $\mathrm{H}_{2}$ with an electrochemical $\mathrm{H}_{2}$ sensor. Since $\mathrm{H}_{2}$ rapidly permeates through biological tissue, measurements are made by simply pressing the sensor tip against the skin above the implant; the response is within $30 \mathrm{~s}$. 
Keywords: Biodegradation, Magnesium alloys, Electrochemical sensor, Hydrogen sensor, Hydrogen, Gas cavity

\section{Introduction}

Biodegradable implants such as plates and screws for bone repair offer many advantages over the permanent stainless steel and titanium implants used today [1-10]. Importantly, implants based on biodegradable materials eventually dissolve when no longer needed, eliminating the need for surgically removing the devices later if complications arise. Magnesium based alloys are an exceptionally good candidate for several reasons. Magnesium is a light weight metal (1.74 - $\left.2.0 \mathrm{~g} / \mathrm{cm}^{3}\right)$ that closely matches the density of bone $\left(1.8-2.1 \mathrm{~g} / \mathrm{cm}^{3}\right)$ [11]. Magnesium based alloys are also typically 4.5 times and 3.3 times less dense than stainless steel and titanium based alloys, respectively [11-12]. Magnesium alloys have a modulus of elasticity of $\sim 45 \mathrm{GPa}$, which is very close to that of human bone $(45-57 \mathrm{GPa})[1,7,13-14]$. These properties lessen the stress shielding and the associated loss of bone density. Moreover, magnesium is biocompatible, and a relatively large amount of magnesium is tolerated by the body without ill effects [15]. Additionally, due to functional roles and presence in bone tissues, magnesium has stimulatory effects on the growth of new bone tissue [11, 16-19]. The rate of biodegradation can be controlled by using alloys or coatings to match the needs of the application $[3,20]$.

Magnesium and its alloys degrade in aqueous environments, generating magnesium $\left(\mathrm{Mg}^{2+}\right)$ and hydroxide $\left(\mathrm{OH}^{-}\right)$ions, as well as hydrogen $\left(\mathrm{H}_{2}\right)$ gas. When the $\mathrm{pH}$ becomes sufficiently basic, $\mathrm{OH}^{-}$reacts with $\mathrm{Mg}^{2+}$ to precipitate as magnesium hydroxide $\left(\mathrm{Mg}(\mathrm{OH})_{2}\right)$ on the surface. One molecule of $\mathrm{H}_{2}$ is liberated for every mole of metallic $\mathrm{Mg}$ that biodegrades. Thus, measuring the evolved $\mathrm{H}_{2}$ allows a direct measurement reflecting the corrosion of magnesium [21]. Because $1 \mathrm{~mL}$ of $\mathrm{H}_{2}$ evolved approximately corresponds to $1 \mathrm{mg}$ of magnesium dissolved [22], measuring 
$\mathrm{H}_{2}$ evolution rate is equivalent to measuring the biodegradation or corrosion rate of a magnesium alloy [23-24]. So far, the measurement of $\mathrm{H}_{2}$ evolution is mostly performed in vitro by measuring the generated $\mathrm{H}_{2}$ volume [21-23]. This method is cumbersome, and moreover, the $\mathrm{H}_{2}$ gas collection instruments often suffer leakage. Monitoring the biodegradation process in vivo can be done by micro-CT, which requires a major equipment investment, and by X-ray absorption, which is also expensive, involves exposure to radiation [8-9, 25-30], and requires further time consuming complex analysis involving understanding the difference in X-ray absorption coefficients of the different corrosion products formed for quantization. Therefore, a simple and effective in vivo $\mathrm{H}_{2}$ sensing method is needed for animal testing of alloys and devices.

Monitoring biodegradation in vivo by sensing the corrosion product $\mathrm{H}_{2}$ has numerous advantages over sensing the other corrosion products $\mathrm{OH}^{-}$and $\mathrm{Mg}^{2+}$. First, only $\mathrm{H}_{2}$ has the possibility of being monitored noninvasively because of its high permeability through skin [3133]. This is a significant advantage compared to the surgical insertion of a sensor as would be the case for $\mathrm{pH}$ or $\mathrm{Mg}^{2+}$. Noninvasive measurement also means that the sensor would not be subject to possible interferences by components of biological fluids or biofouling. Second, no significant background level of $\mathrm{H}_{2}$ exists in mammals that needs to be corrected for. For example, the concentration of $\mathrm{H}_{2}$ in mouse blood is only ca. $1 \mu \mathrm{M}$ [34]. Background level is an issue with $\mathrm{Mg}^{2+}$ where a relatively high concentration exists in vivo $\mathrm{Mg}^{2+}$ concentration in adult serum is 0.75-0.95 mM [35]). A sensor for $\mathrm{Mg}^{2+}$ would need to have sufficient precision to detect small increases due to biodegradation above this substantial background. Also, the commonly used electrochemical sensor for $\mathrm{Mg}^{2+}$, an ion-selective electrode, suffers serious interference from $\mathrm{Ca}^{2+}$, which exits in vivo at a higher concentration (ca. 2.0-2.6 mM in serum [35]). Third, $\mathrm{H}_{2}$ is relatively nonreactive in biological media, making it a robust biodegradation marker [36-40]. By 
comparison, released $\mathrm{OH}^{-}$will be consumed by buffer, which severely compromises the measurement of $\mathrm{pH}$ for monitoring biodegradation. Furthermore, $\mathrm{Mg}^{2+}$ reacts with various anions such as $\mathrm{OH}^{-}$and carbonate to form precipitates and with naturally occurring organic ligands (such as lactate and citrate) and proteins to form complexes that might obscure it from a sensor such as an ion-selective electrode [41-42]. Fourth, a commercially available electrochemical $\mathrm{H}_{2}$ sensor with excellent limit of detection and selectivity already exists [31, 43].

The formation of gas cavities associated with implanted $\mathrm{Mg}$ alloys has been widely reported in literature [44-46]. However, the concentration of $\mathrm{H}_{2}$ in these cavities was not clearly known, as only a few studies using techniques not specific for $\mathrm{H}_{2}$ were done when magnesium was first tested as an implant over 60 years ago [47-48]. Nothing was reported since that time and most researchers assumed that these cavities contain primarily $\mathrm{H}_{2}$ [2, 23, 49-50]. We tested this assumption by implanting rapidly degrading Mg alloy (Mg-4 wt.\%Y-0.5 wt.\%Gd-2 wt.\%Nd-0.5 wt.\%Dy) discs subcutaneously in mice and determining the concentration of $\mathrm{H}_{2}$ gas using an electrochemical $\mathrm{H}_{2}$ sensor that was inserted into the cavities through incisions made in the skin. The results were confirmed by gas chromatography-mass spectrometry (GC-MS) [31]. Two significant discoveries were made: (1) First, the concentration of $\mathrm{H}_{2}$ in the gas cavities was actually very low, even shortly after formation of the cavities. The $\mathrm{H}_{2}$ concentrations in the gas cavities measured with the sensor one, two and five days after surgery ranged from $95 \pm 34 \mu \mathrm{M}$ $(0.22 \pm 0.08$ vol. $\%)$ to $428 \pm 35 \mu \mathrm{M}(0.97 \pm 0.08$ vol. \% $)$. These low levels of $\mathrm{H}_{2}$ were confirmed using GC-MS on samples collected from the gas cavities by a syringe. Thus, the levels of $\mathrm{H}_{2}$ in the gas cavities were found to be consistently less than only $1 \%$. The balance of the gas was carbon dioxide and oxygen, both measured by GC-MS, and presumably nitrogen, which could not be quantified as it was the carrier gas in the GC. These results point to very fast transport of 
$\mathrm{H}_{2}$ directly through the biological tissue surrounding the implant. It should also be noted that $\mathrm{H}_{2}$ is not very soluble in water, the concentration at saturation being only $805 \mu \mathrm{M}$ at $20{ }^{\circ} \mathrm{C}$ at sea level [51-52]. The low $\mathrm{H}_{2}$ levels in the gas cavities can be explained by this fast transport combined with the low solubility of $\mathrm{H}_{2}$ in aqueous biological fluids and cells. (2) Second, measurements made noninvasively by just pressing the sensor tip against the skin covering the implant were similar to those made invasively by inserting the sensor tip inside the cavity. This observation confirms the extraordinarily fast transport of $\mathrm{H}_{2}$ through biological tissues such as skin. Most importantly from a practical point of view, this means that $\mathrm{H}_{2}$ levels in vivo can potentially be tracked noninvasively by a $\mathrm{H}_{2}$ sensor measuring transdermally by simply pressing it against the skin. Realizing that the skin is so permeable to $\mathrm{H}_{2}$ and that the electrochemical $\mathrm{H}_{2}$ sensor is extremely sensitive has indeed opened the pathway to develop non-invasive $\mathrm{H}_{2}$ sensing as an effective way to track in vivo biodegradation rates of magnesium implants [31].

Here we report the transdermal measurement of $\mathrm{H}_{2}$ from three biodegrading alloys implanted subcutaneously in mice with an electrochemical $\mathrm{H}_{2}$ sensor. We also correlate the $\mathrm{H}_{2}$ levels with the biodegradation rates obtained by weight loss of the explanted alloys. To the best of our knowledge, this is the first time that measuring $\mathrm{H}_{2}$ transdermally with a $\mathrm{H}_{2}$ sensor has been a routine part of a subcutaneous evaluation of Mg alloys. The measurements are rapidly made noninvasively by just pressing the sensor tip against the skin covering the implant. No major equipment is required such as with micro-CT and X-ray and moreover, there is no exposure to X-ray radiation. This simple method opens the way to developing non-invasive $\mathrm{H}_{2}$ sensing as an effective way to track biodegradation rates of $\mathrm{Mg}$ and its alloys in vivo and noninvasively.

\section{Experimental}

\subsection{Implant materials}


The Mg alloy ZK 40 with Mg-4 wt\% Zn-0.5 wt\% Zr-1.4 wt\% Cu-0.2 wt \% Fe-0.3 wt\% Mn$1.8 \mathrm{wt} \% \mathrm{Ni}-0.7 \mathrm{wt} \% \mathrm{Si}$ was prepared by a previously described method [6]. AZ31 alloy that contained 2.5-3.5 wt $\% \mathrm{Al}, 0.6-1.4 \mathrm{wt} \% \mathrm{Zn}$ and 0.2-1.0 wt $\% \mathrm{Mn}$ with the remainder being $\mathrm{Mg}$ was purchased from Goodfellow (Oakdale, PA). The processing of the alloy was based on a previous method [4]. Typical preparation of the high purity magnesium single crystal $\mathrm{Mg} 8 \mathrm{H}$ is described below. A crystal grower made by CVD Equipment Corporation was employed as a main tool. The initial poly-crystalline magnesium with purity of $99.95 \%$ (Alfa Aesar) was used as raw material to grow single crystals. Graphite crucible with a tapered shape was used to contain the molten material which was enclosed in an external holder made of a special grade stainless steel. The growth process took place in a vertical quartz tube under argon flow. The tube was surrounded by a vertical crystal furnace. The furnace had two temperature zones to create and control an appropriate temperature gradient in the crucible. The melt was soaked for 8 $\mathrm{h}$ to enable complete homogenization. The single crystal was thereafter grown from the melt by controlled withdrawal of the furnace chamber under a suitable thermal gradient. This technique is known as Bridgman-Stockbarger approach. A typical magnesium single crystal with length of $45 \mathrm{~mm}$, diameter of $6.5 \mathrm{~mm}$ and orientation close to (0001) was used in this study. The crystal was diced into discs of $5 \mathrm{~mm}$ diameter and $2 \mathrm{~mm}$ thickness by electrical discharge machining (EDM). The discs were hand polished using 600 grit and 1200 grit SiC paper in isopropyl alcohol. After every polishing pass, the individual discs were sonicated in ethanol for 2 min and then air dried.

\subsection{Procedures on laboratory mice}

Specific pathogen-free female athymic nude mice were purchased from Harlan Laboratory (Indianapolis, IN) and used when they were 8 to 10 weeks of age. The mice were maintained in a 
facility approved by the American Association for Accreditation of Laboratory Animal Care and in accordance with current regulations and standards of the U.S. Department of Agriculture, U.S. Department of Health and Human Services, and NIH. The animal studies were approved by the Institutional Animal Care and Use Committee (IACUC) and executed according to IACUC guidelines. An in vivo murine subcutaneous study was conducted to explore any acute host response of $\mathrm{AZ31}, \mathrm{ZK} 40$, and $\mathrm{Mg} 8 \mathrm{H}$ samples. Implantation into mice (3 mice/sample type) was performed at the University of Cincinnati. For this test, discs of $5 \mathrm{~mm}$ diameter and $1.4 \mathrm{~mm}$ thickness were sectioned from the AZ31, ZK40, and Mg8H alloy specimens. The disc samples were then sonicated in acetone and air dried. For sterilization, the pellets were placed in $70 \%$ ethanol for $5 \mathrm{~min}$, rinsed with Dulbecco's phosphate buffer saline (DPBS, $\mathrm{KCl} 2.7 \mathrm{mM}, \mathrm{KH}_{2} \mathrm{PO}_{4}$, $(1.5 \mathrm{mM}), \mathrm{NaCl}(138 \mathrm{mM}), \mathrm{Na}_{2} \mathrm{HPO}_{4}$ anhydrous $\left.(8.1 \mathrm{mM}), \mathrm{pH} 7.0\right)$ and then irradiated under UV light for 20 min on each side of the discs. Healthy nude mice were housed under controlled conditions and maintained with a standard diet and water. All the mice were anesthetized with isoflurane and a small skin incision was made to create a subcutaneous pocket on the back of the mouse. Mg alloys were inserted into the pocket, and the incision was closed with surgical staples. After two months, the mice were sacrificed under $\mathrm{CO}_{2}$, and the alloys were explanted for further characterization.

\section{3. $\mathrm{H}_{2}$ measurement by amperometric $\mathrm{H}_{2}$ sensor}

Amperometric $\mathrm{H}_{2}$ measurements were performed using a $\mathrm{H}_{2}$ microsensor ( $50 \mu \mathrm{m}$ tip diameter, $\mathrm{H}_{2}-50$ ) connected to a multimeter (both from Unisense, Aarhus, Denmark) polarized at +1000 $\mathrm{mV}$ for at least $1 \mathrm{~h}$. After a stable current in the low picoampere range was established, the amperometric sensor was ready for use. Before each series of measurements, the $\mathrm{H}_{2}$ microsensor was calibrated following the manufacturer's recommendations. For calibration, high purity $\mathrm{H}_{2}$ 
gas was bubbled through water until $\mathrm{H}_{2}$ saturation was reached. Then, the saturated $\mathrm{H}_{2}$ water solution was diluted to various concentrations with deionized water. For each solution, 6 measurements were made based on the saturation percentage $(0 \%, 20 \%, 40 \%, 60 \%, 80 \%$ and $100 \%$ saturated solution). The steady state current was calculated from the average of the steady state signal data points taken during each measurement. Hydrogen saturated water is $0.8 \mathrm{mM}$ at room temperature $[51,53]$; correspondingly, the diluted $\mathrm{H}_{2}$ containing solutions were calculated based on their percentage saturation. For each measurement, the hydrogen sensor tip was immersed in the $\mathrm{H}_{2}$ calibrant for 3 min and a current vs. $\mathrm{H}_{2}$ concentration calibration curve was plotted. In vivo measurements were converted into $\mathrm{H}_{2}$ concentration based on the calibration plots.

For in vivo measurements, the microsensor was positioned with a micromanipulator [31]. Measurements were taken by touching the sensor tip on the skin above the gas cavity near the implant area and other locations as noted in the figures. As a control, measurements were taken on top of the skin in an area away from the gas cavity such as the tail. The current obtained from the $\mathrm{H}_{2}$ sensor was converted to $\mathrm{H}_{2}$ concentration using a calibration curve generated from known levels of $\mathrm{H}_{2}$ saturated water (vide supra).

2.4. $\mathrm{H}_{2}$ microsensor for transdermal sensing of $\mathrm{H}_{2}$ from subcutaneous magnesium implants in mice

Hydrogen sensing was performed with an electrochemical sensor in which a constant potential is applied to the working electrode and the resulting current is measured (amperometric sensor) $[51,54]$. Hydrogen is detected by its electrochemical oxidation to protons at a platinum electrode inside the sensor:

$$
\mathrm{H}_{2} \rightarrow 2 \mathrm{H}^{+}+2 \mathrm{e}^{-}
$$


The tip of the sensor is very small $(\sim 50 \mu \mathrm{m}$ diameter), which enables measurements to be made at a precise point. The tip contains a plug of silicone rubber membrane through which the $\mathrm{H}_{2}$ passes in order to be detected. This feature makes the sensor extraordinarily specific for $\mathrm{H}_{2}$. The limit of detection $(0.01 \%, 0.1 \mu \mathrm{M}$ in water) is sufficiently low to easily measure the very low levels of $\mathrm{H}_{2}$ that are involved in these experiments.

The sensor was used to make each in vivo measurement by gently pressing the tip against the skin of an anesthetized mouse, either with a precisely adjustable micro positioner as shown in Fig. 1 or by hand. This measurement procedure is similar to that described for non-invasive measurements in our earlier report [31]. Each measurement required about $30 \mathrm{~s}$ for a steady state signal to be achieved. However, to achieve the stablest $\mathrm{H}_{2}$ signal and more accurate measurements, measurements taken for 3 min or longer. The sensor was calibrated before each series of measurements and then again immediately afterwards to be sure the sensor response had not drifted.

\subsection{Statistical analysis}

$\mathrm{H}_{2}$ concentrations are expressed as the mean $\pm \mathrm{SD}$ (standard deviation) unless indicated otherwise. For statistical analysis of $\mathrm{H}_{2}$ generated by the magnesium alloy corrosion, measurements were made on 3 mice per sample type (AZ31, Mg8H and ZK40). The obtained $\mathrm{H}_{2}$ concentration means were statistically assessed for significant differences using the Student's t test. The comparison of $\mathrm{H}_{2}$ concentrations at different spots on mice with the same/different implanted subcutaneously alloys was made based on the means where a confidence level of $95 \%$ or greater was considered significant.

\section{Results and discussion}




\subsection{Transdermal sensing of $\mathrm{H}_{2}$ from a medium biodegrading subcutaneous $\mathrm{Mg}$ implant}

Transdermal $\mathrm{H}_{2}$ sensing was first explored using $\mathrm{Mg} 8 \mathrm{H}$ polycrystalline alloy. The biodegradation rate of this alloy is sufficiently fast to create enough $\mathrm{H}_{2}$ gas to form visible gas cavities protruding from the skin when implanted subcutaneously in mice. Gas cavities with this alloy became visible within $24 \mathrm{~h}$ after implantation and increased in size until they became quite large. $\mathrm{H}_{2}$ measurements were made once a week after implantation for all the alloys (vide infra). Fig. 2a shows the gas cavity of a nude mouse 1 week after implanting a disc of $\mathrm{Mg} 8 \mathrm{H}$. The gas was released after 1 week due to animal welfare concerns associated with the very large size of gas cavities.

The sensor responses to positioning the tip at multiple locations on the mouse as marked in Fig. $2 \mathrm{a}$ - on the cavity, immediately adjacent to the cavity, and far from the cavity - are shown in Fig. 2b. The $\mathrm{H}_{2}$ permeating through the skin of the mouse on top of the cavity gives a substantial signal that is easily detected. The sensor responds quickly, giving a signal for $\mathrm{H}_{2}$ in about $30 \mathrm{~s}$. However, to achieve the stablest $\mathrm{H}_{2}$ signal, measurements were taken for 3 min. Our previous

study showed that these levels are representative of $\mathrm{H}_{2}$ concentrations found inside the cavity [31]. $\mathrm{H}_{2}$ levels measured at the points indicated in Fig. 2a provide a "map" of $\mathrm{H}_{2}$ permeation through the skin. The noise section is due to the motion of the $\mathrm{H}_{2}$ amperometric sensor when it was moved to a different position on the mouse skin. The average responses of the current for each measurement point are shown graphically in Fig. 2c after conversion to concentrations of $\mathrm{H}_{2}$ obtained from the currents by means of a calibration curve. Error bars are standard deviations for measurements made on three mice $(\mathrm{N}=3)$ (vide infra). As expected the highest levels of $\mathrm{H}_{2}$ (100 - $200 \mu \mathrm{M}$ ) were found when the sensor tip was placed directly on the cavity that surrounds the implant (points 3-6 and 11-15). Some variability in $\mathrm{H}_{2}$ was found depending on exactly 
where the tip was placed on the cavity. This variability might be due to variation in the skin thickness due to stretching from the inflation by the gas or variation in the inner structure of the cavity, which was reported earlier [31]. When the sensor tip was moved off of the cavity, $\mathrm{H}_{2}$ was still detected from the skin immediately adjacent to the cavity, but at considerably lower concentrations (points 16-17). Measurements toward the head and the tail (points 1, 2 and 7-10) gave signals that were just above blank which was measured in the air. The low $\mathrm{H}_{2}$ concentration of 1.0-7.3 $\mu \mathrm{M}$ measured at distances far from the implant, such as the tail and head, is attributed to a background signal arising from aerobic bacteria in the food digestion process [34]. $\mathrm{H}_{2}$ concentrations measured in control mice with no implant showed this same very low level of $\mathrm{H}_{2}$ at all points measured including the region of the back where implants were positioned in the test mice. This background level in the control mice and in the test mice at distances far from the implant also agrees with hydrogen concentrations of $1.0 \mu \mathrm{M}$ in literature reports [34]. This observation suggests that $\mathrm{H}_{2}$ transported around the body by the vascular system is detected, although the concentration is very low.

To test the repeatability of the $\mathrm{H}_{2}$ measurements for a specific point on the cavity, the $\mathrm{H}_{2}$ was measured at the same spot with and without the micromanipulator (hand held). Six measurements using the micromanipulator gave an average value of $261.4 \pm 17.3 \mathrm{pA}$, whereas four measurements made by hand gave an average value of $243.0 \pm 18.8 \mathrm{pA}$. These results show that measured values of $\mathrm{H}_{2}$ at a particular point are very reproducible and that the hand held approach is almost as good to the using of micromanipulator (Fig. S1). In order to get the best precision, the sensor tip must be gently pressed against the mouse skin in a reproducible manner. Measurements made with the tip held only slightly above the surface give lower values because of the fast diffusion of $\mathrm{H}_{2}$ in air. These results show that $\mathrm{H}_{2}$ transdermal detection is indeed 
repeatable.

A major strength of this non-invasive method for detecting in vivo biodegradation is the ability to perform repeated measurements on the same animal over time. This was demonstrated by monitoring $\mathrm{H}_{2}$ for three mice $(\mathrm{N}=3$ ) over the 2-month period during which the alloys remained implanted. The $\mathrm{H}_{2}$ concentration was measured at the skin centered above the implanted $\mathrm{Mg} 8 \mathrm{H}$ once a week. As seen from Fig. 2d, $\mathrm{H}_{2}$ concentration was similar for the first 3 weeks, then it decreased with time. $\mathrm{H}_{2}$ concentration decreased to $50 \%$ at 8 weeks compared to the first week. This decreasing $\mathrm{H}_{2}$ concentration with time is expected due to the slowing corrosion caused by the formation of an increasingly thick corrosion layer of $\operatorname{Mg}(\mathrm{OH})_{2}$, and $\mathrm{MgCO}_{3}$ that coats the implant surface [31].

\subsection{Transdermal sensing of $\mathrm{H}_{2}$ from a slowly biodegrading subcutaneous $\mathrm{Mg}$ implant}

A more slowly corroding alloy of magnesium, AZ31 that generates $\mathrm{H}_{2}$ too slowly to form a visible cavity was also examined. As shown in Fig. 3a, no $\mathrm{H}_{2}$ cavity is discernable on the mouse, just a bump showing the outline of the implanted $\mathrm{Mg}$ disc. The absence of the gas cavity confirms that the biodegradation of AZ31 is much slower than that of Mg8H. Figs. 3b-c show the real-time sensor responses and hydrogen levels for a variety of measurement spots from head to tail and going across the implant area, similar to the $\mathrm{Mg} 8 \mathrm{H}$ alloy navigation. Importantly, the $\mathrm{H}_{2}$ generated by degradation of the implanted AZ31 permeating through the skin was still easily measureable by the $\mathrm{H}_{2}$ microsensor, albeit the current levels were much lower. As seen from Fig. $3 b-c$, the $\mathrm{H}_{2}$ concentration is highest through the skin directly over the center of the implant. Although the $\mathrm{H}_{2}$ concentration at the edge area near the implant is lower, a measureable signal is still obtained. The current is up to $171 \mathrm{pA}(36.4 \mu \mathrm{M})$ at the skin centered above the implanted AZ31 (spot 6); the current decreased to $66 \mathrm{pA}(29.6 \mu \mathrm{M})$ and $62 \mathrm{pA}(29.2 \mu \mathrm{M})$ for spots 5 and 7 , 
respectively. As the distance increased from the implant, lower $\mathrm{H}_{2}$ concentration was detected. At the head area (spot 1), a very low concentration of $\mathrm{H}_{2}$ was detected, which is similar to levels found in the blood for a mouse without any biodegradable implant [34]. Similarly, at spots 2-4 and 8-9, a very low concentration of $\mathrm{H}_{2}$ was detectable. From these measurements, it is clearly seen that $\mathrm{H}_{2}$ permeating through the skin is detectable even when no bubble is observed, although the $\mathrm{H}_{2}$ concentration is very low. This observation points to extraordinary fast transport of $\mathrm{H}_{2}$ through the skin. It also confirms that $\mathrm{H}_{2}$ release from the implant degradation process is occurring even when no gas cavity is visible.

$\mathrm{H}_{2}$ levels were monitored over the 2-month period during which the alloy remained implanted using the same procedure described above for $\mathrm{Mg} 8 \mathrm{H}$. The results in Fig. $3 \mathrm{~d}$ show a relatively small decrease in $\mathrm{H}_{2}$ concentration over the 2 months compared to $\mathrm{Mg} 8 \mathrm{H}$ (Fig. 2d). Even though the decrease is considerably less, statistical evaluation using the student's $t$ test shows a significant difference between the first and last measurements at the $95 \%$ confidence level. This would indicate a consistent corrosion rate that decreased only gradually during the 2-month period. The smaller decrease in $\mathrm{H}_{2}$ concentration is due to the slower corrosion rate of AZ31 compared to $\mathrm{Mg} 8 \mathrm{H}$. Since much less $\mathrm{H}_{2}$ gas was generated during the corrosion process of AZ31, the weekly release of the gas bubbles was not necessary. In addition, the corrosion layer of $\mathrm{Mg}(\mathrm{OH})_{2}$ and $\mathrm{MgCO}_{3}$ on the explanted AZ31 samples was much thinner compared to the faster corroding Mg8H samples.

\subsection{Transdermal sensing of $\mathrm{H}_{2}$ from a very rapidly biodegrading subcutaneous $\mathrm{Mg}$ implant}

For comparison, an exceptionally fast corroding alloy, ZK40, was also examined. The faster corrosion rate expectedly released more $\mathrm{H}_{2}$, which resulted in much higher signals from the sensor as shown in Fig. S2. In the case of ZK40, the $\mathrm{H}_{2}$ sensor current is up to 620 pA $(360 \mu \mathrm{M})$ 
at the bubble center, which is much higher than that in the case of AZ31 (171 pA, $36.4 \mu \mathrm{M})$ at a similar position. The $\mathrm{H}_{2}$ sensor currents at the edge area of the bubble are also higher, $249 \mathrm{pA}$ $(197 \mu \mathrm{M})$ and $121 \mathrm{pA}(140 \mu \mathrm{M})$ for ZK40 and AZ31, respectively.

$\mathrm{H}_{2}$ levels for $\mathrm{ZK} 40$ over the 2-month period are shown in Fig. S2d. ZK40 showed $\mathrm{H}_{2}$ concentration decreasing almost $75 \%$ by 8 weeks compared to the first week after implantation. This fastest corroding alloy showed the highest initial concentrations of $\mathrm{H}_{2}$, and the greatest decrease over the 8-week period.

Comparing the three alloys, the maximum $\mathrm{H}_{2}$ concentration generated by the three alloys at the beginning of the study and the percentage decrease in $\mathrm{H}_{2}$ over the 2-month period both decrease in the order of $\mathrm{ZK} 40>\mathrm{Mg} 8 \mathrm{H}>\mathrm{AZ} 31$. This tracked the corrosion rate as determined by weight loss. Moreover, the layer of precipitation on the explanted alloys is much thicker for the faster corroding implant.

Based on the results from these mice with different alloys, it is seen that the $\mathrm{Mg}$ implants with faster corrosion rates generate more hydrogen in a given period, resulting in a larger cavity size and higher concentration of $\mathrm{H}_{2}$ permeating through the mouse skin above the implant as measured by the sensor. Thus, the electrochemical sensor for $\mathrm{H}_{2}$ appears to be useful for detecting the relative biodegradation rates of different $\mathrm{Mg}$ alloys in vivo by a non-invasive procedure.

\subsection{Correlation of $\mathrm{H}_{2}$ electrochemical sensor measurement and corrosion rate}

In order to determine how well the $\mathrm{H}_{2}$ sensor measurements correlate with the corrosion rate of the alloys, actual corrosion rates were determined by the weight losses after 2 months implantation. A comparison of the maximum $\mathrm{H}_{2}$ concentration measured by the $\mathrm{H}_{2}$ sensor at the center of the cavity, or directly above the implanted sample, with the weight loss is shown in Fig. 
4. Weight loss measurements show that the order of corrosion rate over the 2-month period is ZK40 > Mg8H > AZ31 and that ZK40 biodegrades much faster than AZ31. The weight losses are $75 \%, 32.5 \%$, and $2.4 \%$ for $\mathrm{ZK} 40, \mathrm{Mg} 8 \mathrm{H}$ and AZ31, respectively. The graph shows that the maximum $\mathrm{H}_{2}$ concentration measured is proportional to the weight loss percentage, which is expected because the higher biodegradation rate produces more $\mathrm{H}_{2}$. The $\mathrm{H}_{2}$ measurements shown in Fig. 4 were recorded one week after implantation. Measurements made at this time gave the best correlation between $\mathrm{H}_{2}$ levels and weight loss than measurements made at other times during the study. This procedure avoided complications posed by routinely releasing gas from the cavities each week to relieve any discomfort to the mice, slowing in the corrosion rate over the two-month period due to formation of a corrosion layer of $\mathrm{Mg}(\mathrm{OH})_{2}$ and $\mathrm{MgCO}_{3}$ on the surface of the implant and the decreasing mass of the implant especially for the faster corroding alloys, and variation in the time interval between measurements because of scheduling issues.

The sizes of the gas cavities were measured every week as a part of the animal protocol. The gas cavity volume was estimated based on skin surface dimensions measured with a Vernier caliper. However, correlation of the gas cavity volumes with the $\mathrm{H}_{2}$ concentrations obtained with the sensor was poor. We attribute this to $\mathrm{H}_{2}$ in the cavities being released every week for the comfort of the test animals.

In general, the $\mathrm{H}_{2}$ levels decreased over the time course of the study as corrosion slowed. The $\mathrm{H}_{2}$ levels measured throughout the study for the slowly corroding AZ31 were relatively consistent from week to week, whereas the levels for the very rapidly corroding ZK40 alloy decreased substantially from the beginning of the study to the end when much of the $\mathrm{Mg}$ had corroded.

\section{Conclusion}


The remarkably rapid transport of $\mathrm{H}_{2}$ through skin enables the measurement of $\mathrm{H}_{2}$ concentration transdermally at the surface of the skin above a biodegrading magnesium sample implanted subcutaneously in mice. Although the concentrations are very low (ca. 30 to $400 \mu \mathrm{M}$ in these studies), the electrochemical $\mathrm{H}_{2}$ sensor has adequate limit of detection to easily measure these levels. Measurements are rapid, taking about $30 \mathrm{~s}$ for the sensor to reach a steady reading. Measured $\mathrm{H}_{2}$ levels correlate with the corrosion rates as determined by weight loss of explanted samples after being implanted for 2 months. Thus, $\mathrm{H}_{2}$ sensing shows promise as an effective means for monitoring the biodegradation of magnesium alloys in vivo. $\mathrm{H}_{2}$ sensing has advantages over traditional methods of monitoring biodegradation rate such as weight loss of explanted samples, X-ray measurements, and micro-CT. Compared to weight loss, it gives a measure of biodegradation rate at the time of measurement rather than integrated over the entire time of implantation. Compared to X-ray and micro-CT, the instrumentation is much less expensive and involves no exposure to radiation. The main fundamental limitation of sensing $\mathrm{H}_{2}$ transdermally is the maximum tissue depth from implant to skin surface that the $\mathrm{H}_{2}$ can permeate through to produce a sufficiently high concentration for detection by pressing the sensor tip to the skin. Thus, this technique might not be applicable to deep implants such as on the thigh bone where permeation through a thick muscle layer would be necessary. The applicability would also be expected to vary among animals because of physical differences. Practical considerations include the need for periodic calibration of the sensor with $\mathrm{H}_{2}$ standards at appropriate intervals to ensure that measurements are accurate. In addition, the membrane permeability of the $\mathrm{H}_{2}$ microsensor changes with time, causing loss in sensitivity of as much as $50 \%$ over several months.

Overall, these results lay the foundation for routine $\mathrm{H}_{2}$ measurement as part of the in vivo testing of devices fabricated from magnesium. The $\mathrm{H}_{2}$ sensor should give a quick measure of 
transdermal $\mathrm{H}_{2}$ levels that arise during biodegradation of an implant such as a plate used for repair of a broken arm, wrist, leg, ankle, foot, or jaw where the metal is directly under the skin of the test animal.

The application of this technology to human patients would depend on the depth and permeability of biological tissue above the implant that $\mathrm{H}_{2}$ must pass through to be detected. Human skin is generally thicker than mouse skin [55-59] and also less permeable [60-61]. The thickness of mouse skin (epidermis and dermis) is approximately 200-500 $\mu \mathrm{m}$, which is close to that of human skin in some locations such as the eyelid and neck area (380-700 $\mu \mathrm{m})$ [55-58]. The average epidermis thickness is $83.7 \mu \mathrm{m}$ for human skin compared to only $9.4-13.3 \mu \mathrm{m}$ for mouse skin [57-58], and the average dermis thickness for human skin is $908-1339 \mu \mathrm{m}$ compared to only $200-500 \mu \mathrm{m}$ for mouse skin $[55,59]$. The primary permeability barrier is the outermost layer, the stratum corneum. Clearance of non metabolized solutes from skin is the sum of three separate processes - permeation through the stratum corneum, blood capillary clearance and lymphatic clearance [62]. The fraction of the solute escaping from the skin surface is consequently a ratio of the stratum corneum clearance to the total clearance, rather than being determined by implantation depth only. However, it is fair to say that the deeper the implantation, the lower this ratio will be.

If we take the common rule-of-thumb that rodent stratum corneum is 3-4 times more permeable than human stratum corneum for low molecular weight solutes, and assume furthermore that capillary and lymphatic clearances in human skin and mouse skin are comparable, then a first estimate of the escape rate of $\mathrm{H}_{2}$ from the skin surface of a human subject with an implant just below the skin surface would be 3-4 times lower than those observed in mouse. This prediction would suggest that it could still be measured using the present $\mathrm{H}_{2}$ 
sensors. It is worth verifying experimentally because of the several assumptions built into this estimate. Consequently, transdermal $\mathrm{H}_{2}$ measurement would be expected to be effective for implants directly beneath the skin, such as on the back of the hand and foot, appendages such as fingers and toes, and on parts of bones such as the arm that are near the surface. The $\mathrm{H}_{2}$ response would be expected to diminish for deeper implants, especially where the $\mathrm{H}_{2}$ must permeate through muscle with blood vessels that would carry the $\mathrm{H}_{2}$ away. The noninvasive feature and simple procedure leads to the possibility of use for point-of-care measurements of biodegradation rates for implants near the skin in humans as part of routine checks at a doctor's office during the healing process.

\section{Acknowledgement}

The authors thank the National Science Foundation (NSF ERC 0812348) for financial support. PNK also acknowledges the support of the Edward R. Weidlein Chair Professorship Funds. The authors thank Professor Gerald B. Kasting, James L. Winkle College of Pharmacy, University of Cincinnati Academic Health Center for helpful discussions about the characteristics of mouse skin compared to human skin.

\section{References}

[1] Cha PR, Han HS, Yang GF, Kim YC, Hong KH, Lee SC, Jung JY, Ahn JP, Kim YY, Cho SY, Byun JY, Lee KS, Yang SJ, Seok HK. Biodegradability engineering of biodegradable Mg alloys: Tailoring the electrochemical properties and microstructure of constituent phases. Sci Rep 2013;3:2367.

[2] Zhang S, Zhang X, Zhao C, Li J, Song Y, Xie C, Tao H, Zhang Y, He Y, Jiang Y, Bian Y. Research on an MgZn alloy as a degradable biomaterial. Acta Biomater 2010;6:626-640.

[3] Chen Y, Xu Z, Smith C, Sankar J. Recent advances on the development of magnesium alloys for biodegradable implants. Acta Biomater 2014;10:4561-4573.

[4] Chou DT, Hong D, Saha P, Ferrero J, Lee B, Tan ZQ, Dong ZY, Kumta PN. In vitro and in vivo corrosion, cytocompatibility and mechanical properties of biodegradable Mg-Y-Ca-Zr alloys as implant materials. Acta Biomater 2013;9:8518-8533.

[5] Henderson SE, Verdelis K, Maiti S, Pal S, Chung WL, Chou DT, Kumta PN, Almarza AJ. Magnesium alloys as a biomaterial for degradable craniofacial screws. Acta Biomater 2014;10:2323-2332.

[6] Hong D, Saha P, Chou DT, Lee B, Collins BE, Tan ZQ, Dong ZY, Kumta PN. In vitro degradation and cytotoxicity response of $\mathrm{Mg}-4 \% \mathrm{Zn}-0.5 \% \mathrm{Zr}$ (ZK40) alloy as a potential biodegradable material. Acta Biomater 2013;9:8534-8547. 
[7] Poinern E, Brundavanam S, Fawcett D. Biomedical magnesium alloys: A review of material properties, surface modifications and potential as a biodegradable orthopaedic implant. Am J Biomed Eng 2012;2:218-240.

[8] Witte F, Fischer J, Nellesen J, Crostack HA, Kaese V, Pisch A, Beckmann F, Windhagen H. In vitro and in vivo corrosion measurements of magnesium alloys. Biomaterials 2006;27:1013-1018.

[9] Witte F, Kaese V, Haferkamp H, Switzer E, Meyer-Lindenberg A, Wirth CJ, Windhagen H. In vivo corrosion of four magnesium alloys and the associated bone response. Biomaterials 2005;26:3557-3563. [10] Yun YH, Dong Z, Lee N, Liu Y, Xue D, Guo X, Kuhlmann J, Doepke A, Halsall HB, Heineman W, Sundaramurthy S, Schulz MJ, Yin Z, Shanov V, Hurd D, Nagy P, Li W, Fox C. Revolutionizing biodegradable metals. Mater Today 2009;12:22-32.

[11] Staiger MP, Pietak AM, Huadmai J, Dias G. Magnesium and its alloys as orthopedic biomaterials: A review. Biomaterials 2006;27:1728-1734.

[12] Seal CK, Vince K, Hodgson MA. Biodegradable surgical implants based on magnesium alloys - A review of current research. Iop Conf Ser-Mat Sci 2009:012011.

[13] Razavi M, Fathi MH, Meratian M. Microstructure, mechanical properties and bio-corrosion evaluation of biodegradable AZ91-FA nanocomposites for biomedical applications. Mat Sci Eng a-Struct 2010;527:6938-6944.

[14] Feng AL, Han Y. The microstructure, mechanical and corrosion properties of calcium polyphosphate reinforced ZK60A magnesium alloy composites. J Alloy Compd 2010;504:585-593.

[15] Saris NEL, Mervaala E, Karppanen H, Khawaja JA, Lewenstam A. Magnesium - An update on physiological, clinical and analytical aspects. Clin Chim Acta 2000;294:1-26.

[16] Zreiqat H, Howlett CR, Zannettino A, Evans P, Schulze-Tanzil G, Knabe C, Shakibaei M. Mechanisms of magnesium-stimulated adhesion of osteoblastic cells to commonly used orthopaedic implants. J Biomed Mater Res 2002;62:175-184.

[17] Zreiqat H, Shakibaei ME, Evans P, Knabe C, Howlett CR. Mechanisms of magnesium-stimulated adhesion of osteoblastic cells to commonly used orthopaedic implants. J Bone Miner Res 2001;16:S328S328.

[18] Yamasaki Y, Yoshida Y, Okazaki M, Shimazu A, Uchida T, Kubo T, Akagawa Y, Hamada Y, Takahashi J, Matsuura N. Synthesis of functionally graded $\mathrm{MgCO}_{3}$ apatite accelerating osteoblast adhesion. J Biomed Mater Res 2002;62:99-105.

[19] Yamasaki Y, Yoshida Y, Okazaki M, Shimazu A, Kubo T, Akagawa Y, Uchida T. Action of $\mathrm{FGMgCO}_{3}$ Apcollagen composite in promoting bone formation. Biomaterials 2003;24:4913-4920.

[20] Hornberger H, Virtanen S, Boccaccini AR. Biomedical coatings on magnesium alloys - A review. Acta Biomater 2012;8:2442-2455.

[21] Atrens A, Song GL, Liu M, Shi ZM, Cao FY, Dargusch MS. Review of recent developments in the field of magnesium corrosion. Adv Eng Mater 2015;17:400-453.

[22] Song G. Recent progress in corrosion and protection of magnesium alloys. Adv Eng Mater 2005;7:563-586.

[23] Song G. Control of biodegradation of biocompatable magnesium alloys. Corros Sci 2007;49:16961701.

[24] Zeng R, Dietzel W, Witte F, Hort N, Blawert C. Progress and challenge for magnesium alloys as biomaterials. Adv Eng Mater 2008;10:B3-B14.

[25] Kraus T, Fischerauer SF, Hanzi AC, Uggowitzer PJ, Loffler JF, Weinberg AM. Magnesium alloys for temporary implants in osteosynthesis: In vivo studies of their degradation and interaction with bone. Acta Biomater 2012;8:1230-1238.

[26] Fischerauer SF, Kraus T, Wu X, Tangl S, Sorantin E, Hanzi AC, Loffler JF, Uggowitzer PJ, Weinberg AM. In vivo degradation performance of micro-arc-oxidized magnesium implants: A micro-CT study in rats. Acta Biomater 2013;9:5411-5420. 
[27] Dziuba D, Meyer-Lindenberg A, Seitz JM, Waizy $H$, Angrisani N, Reifenrath J. Long-term in vivo degradation behaviour and biocompatibility of the magnesium alloy ZEK100 for use as a biodegradable bone implant. Acta Biomater 2013;9:8548-8560.

[28] Yang J, Cui F, Lee I, Zhang Y, Yin Q, Xia H, Yang S. In vivo biocompatibility and degradation behavior of $\mathrm{Mg}$ alloy coated by calcium phosphate in a rabbit model. J Biomater Appl 2012;27:153-164.

[29] Wang Y, Zhu Z, He Y, Jiang Y, Zhang J, Niu J, Mao L, Yuan G. In vivo degradation behavior and biocompatibility of Mg-Nd-Zn-Zr alloy at early stage. Int J Mol Med 2012;29:178-184.

[30] Hou L, Li Z, Pan Y, Du L, Li X, Zheng Y, Li L. In vitro and in vivo studies on biodegradable magnesium alloy. Prog Nat Sci-Mater 2014;24:466-471.

[31] Kuhlmann J, Bartsch I, Willbold E, Schuchardt S, Holz O, Hort N, Hoche D, Heineman WR, Witte F. Fast escape of hydrogen from gas cavities around corroding magnesium implants. Acta Biomater 2013;9:8714-8721.

[32] Zhao D, Wang $T$, Heineman WR. Advances in $\mathrm{H}_{2}$ sensors for bioanalytical applications. Trends in Analytical Chemistry 2016; http://dx.doi.org/doi: 10.1016/j.trac.2016.01.015.

[33] Zhao D, Wang T, Guo X, Kuhlmann J, Doepke A, Dong Z, Shanov VN, Heineman WR. Monitoring biodegradation of magnesium implants with sensors. JOM-J Min Met S 2016; In press.

[34] Nakashima-Kamimura N, Mori T, Ohsawa I, Asoh S, Ohta S. Molecular hydrogen alleviates nephrotoxicity induced by an anti-cancer drug cisplatin without compromising anti-tumor activity in mice. Cancer Chemoth Pharm 2009;64:753-761.

[35] Kaplan LA, Pesce AJ. Clinical Chemistry: Theory, Analysis, Correlation 1996;Morsby Inc.:528-592.

[36] Ohsawa I, Ishikawa M, Takahashi K, Watanabe M, Nishimaki K, Yamagata K, Katsura K, Katayama Y, Asoh S, Ohta S. Hydrogen acts as a therapeutic antioxidant by selectively reducing cytotoxic oxygen radicals. Nat Med 2007;13:688-694.

[37] Ostojic SM. Molecular hydrogen in hports medicine: new therapeutic perspectives. Int J Sports Med 2015;36:273-279.

[38] Ostojic SM. Molecular hydrogen: An inert gas turns clinically effective. Ann Med 2015;47:301-304.

[39] Ohta S. Molecular hydrogen as a preventive and therapeutic medical gas: initiation, development and potential of hydrogen medicine. Pharmacol Therapeut 2014;144:1-11.

[40] Ohta S. Recent progress toward hydrogen medicine: potential of molecular hydrogen for preventive and therapeutic applications. Curr Pharm Design 2011;17:2241-2252.

[41] Blaquiere C, Berthon G. Speciation studies in relation to magnesium bioavailability - formation of $\mathrm{Mg}(\mathrm{li})$ complexes with glutamate, aspartate, glycinate, lactate, pyroglutamate, pyridoxine and citrate, and appraisal of their potential significance towards magnesium gastrointestinal absorption. Inorg Chim a-Bioinor 1987;135:179-189.

[42] Johnson CK. X-ray crystal analysis of the substrates of aconitase. V. Magnesium citrate decahydrate $\left[\mathrm{Mg}\left(\mathrm{H}_{2} \mathrm{O}\right)_{6}\right]\left[\mathrm{MgC}_{6} \mathrm{H}_{5} \mathrm{O}_{7}\left(\mathrm{H}_{2} \mathrm{O}\right)\right]_{2} 2 \mathrm{H}_{2} \mathrm{O}$. Acta crystallographica 1965;18:1004-1018.

[43] Pelzer M, Larsen M, Friedrich PF, Bishop AT. Measurement of bone blood flow using the hydrogen washout technique - Part I: Quantitative evaluation of tissue perfusion in the laboratory rat. J Orthopaed Res 2008;26:741-745.

[44] Witte F, Reifenrath J, Muller PP, Crostack HA, Nellesen J, Bach FW, Bormann D, Rudert M. Cartilage repair on magnesium scaffolds used as a subchondral bone replacement. Materialwiss Werkst 2006;37:504-508.

[45] Kaya RA, Cavusoglu H, Tanik C, Kaya AA, Duygulu O, Mutlu Z, Zengin E, Aydin Y. The effects of magnesium particles in posterolateral spinal fusion: an experimental in vivo study in a sheep model. J Neurosurg-Spine 2007;6:141-149.

[46] Von Der Hoh N, Bormann D, Lucas A, Denkena B, Hackenbroich C, Meyer-Lindenberg A. Influence of different surface machining treatments of magnesium-based resorbable implants on the degradation behavior in rabbits. Adv Eng Mater 2009;11:B47-B54. 
[47] McBride E. Absorbable metal in bone surgerya further report on the use of magnesium alloys J Amer Med Assoc 1938;111:2464-2467.

[48] McCord CP, Prendergast JJ, Meek SF, Harrold GC. Chemical gas gangrene from metallic magnesium. Ind Med 1942;11:71-76.

[49] Erdmann N, Bondarenko A, Hewicker-Trautwein M, Angrisani N, Reifenrath J, Lucas A, MeyerLindenberg A. Evaluation of the soft tissue biocompatibility of $\mathrm{MgCa0} .8$ and surgical steel $316 \mathrm{~L}$ in vivo: a comparative study in rabbits. Biomed Eng Online 2010;9:63.

[50] Li Z, Gu X, Lou S, Zheng Y. The development of binary Mg-Ca alloys for use as biodegradable materials within bone. Biomaterials 2008;29:1329-1344.

[51] UNISENSE. Hydrogen sensor user manual 2014:1-24.

[52] Seo T, Kurokawa R, Sato B. A convenient method for determining the concentration of hydrogen in water: use of methylene blue with colloidal platinum. Med Gas Res 2012;2:doi:10.1186/2045-99121182-1181.

[53] Tomoki Seo, Ryosuke Kurokawa, Sato aB. A convenient method for determining the concentration of hydrogen in water: use of methylene blue with colloidal platinum. Med Gas Res 2012;2:1-6.

[54] Korotcenkov G, Do Han S, Stetter JR. Review of electrochemical hydrogen sensors. Chem Rev 2009;109:1402-1433.

[55] Azzi L, El-Alfy M, Martel C, Labrie F. Gender differences in mouse skin morphology and specific effects of sex steroids and dehydroepiandrosterone. J Invest Dermatol 2005;124:22-27.

[56] Ha RY, Nojima K, Adams WP, Brown SA. Analysis of facial skin thickness: Defining the relative thickness index. Plast Reconstr Surg 2005;115:1769-1773.

[57] Sandby-Moller J, Poulsen T, Wulf HC. Epidermal thickness at different body sites: Relationship to age, gender, pigmentation, blood content, skin type and smoking habits. Acta Derm-Venereol 2003;83:410-413.

[58] Koehler MJ, Vogel T, Elsner P, Konig K, Buckle R, Kaatz M. In vivo measurement of the human epidermal thickness in different localizations by multiphoton laser tomography. Skin Res Technol 2010;16:259-264.

[59] Crisan D, Lupsor M, Boca A, Crisan M, Badea R. Ultrasonographic assessment of skin structure according to age. Indian J Dermatol Venereol Leprol 2012;78:519.

[60] Durrheim H, Flynn GL, Higuchi WI, Behl CR. Permeation of hairless mouse skin .1. Experimental methods and comparison with human epidermal permeation by alkanols. J Pharm Sci 1980;69:781-786.

[61] Ghosh B, Reddy LH, Kulkarni RV, Khanam J. Comparison of skin permeability of drugs in mice and human cadaver skin. Indian J Exp Biol 2000;38:42-45.

[62] Ibrahim R, Nitsche JM, Kasting GB. Dermal clearance model for epidermal bioavailability calculations. J Pharm Sci 2012;101:2094-2108. 
Fig. 1. $\mathrm{H}_{2}$ microsensor assembled on a micromanipulator for measuring $\mathrm{H}_{2}$ transdermally from a Mg alloy implanted subcutaneously in a mouse. The sensor tip is in direct contact with the mouse skin.

Fig. 2. $\mathrm{H}_{2}$ measurements on an anaesthetized nude mouse with polycrystalline $\mathrm{Mg} 8 \mathrm{H}$ implanted subcutaneously 1 week after implantation. (a) Photograph of mouse with measurement points marked and numbered. (b) Instant current responses corresponding to numbered points in (a). (c) $\mathrm{H}_{2}$ concentrations measured at each point as determined from a calibration curve. BL is the measurement in air. Error bars are standard deviations for measurements made on three mice $\left(\mathrm{N}=3\right.$ ) (vide infra). (d) $\mathrm{H}_{2}$ concentration monitored weekly during the 8-week study for $\mathrm{Mg} 8 \mathrm{H}(\mathrm{N}=3)$. A single measurement was made centered directly above the implant for each mouse.

Fig. 3. $\mathrm{H}_{2}$ measurements on an anaesthetized nude mouse with AZ31 implanted subcutaneously 1 week after implantation. (a) Photograph of mouse with measurement points marked and numbered. (b) Instant currents responses corresponding to numbered points in (a). (c) $\mathrm{H}_{2}$ concentrations measured at each point as determined from a calibration curve. BL is the measurement in air. (d) $\mathrm{H}_{2}$ concentration monitored weekly during the 8-week study for AZ31 $(\mathrm{N}=3)$. A single measurement was made centered directly above the implant for each mouse.

Fig. 4. The correlation of weight loss percentage after 2 months implanted and maximum $\mathrm{H}_{2}$ concentration measured in vivo by the $\mathrm{H}_{2}$ sensor for three alloys after the first week of implantation. Error bars are standard deviations for measurements made on three mice $(\mathrm{N}$ =3). 


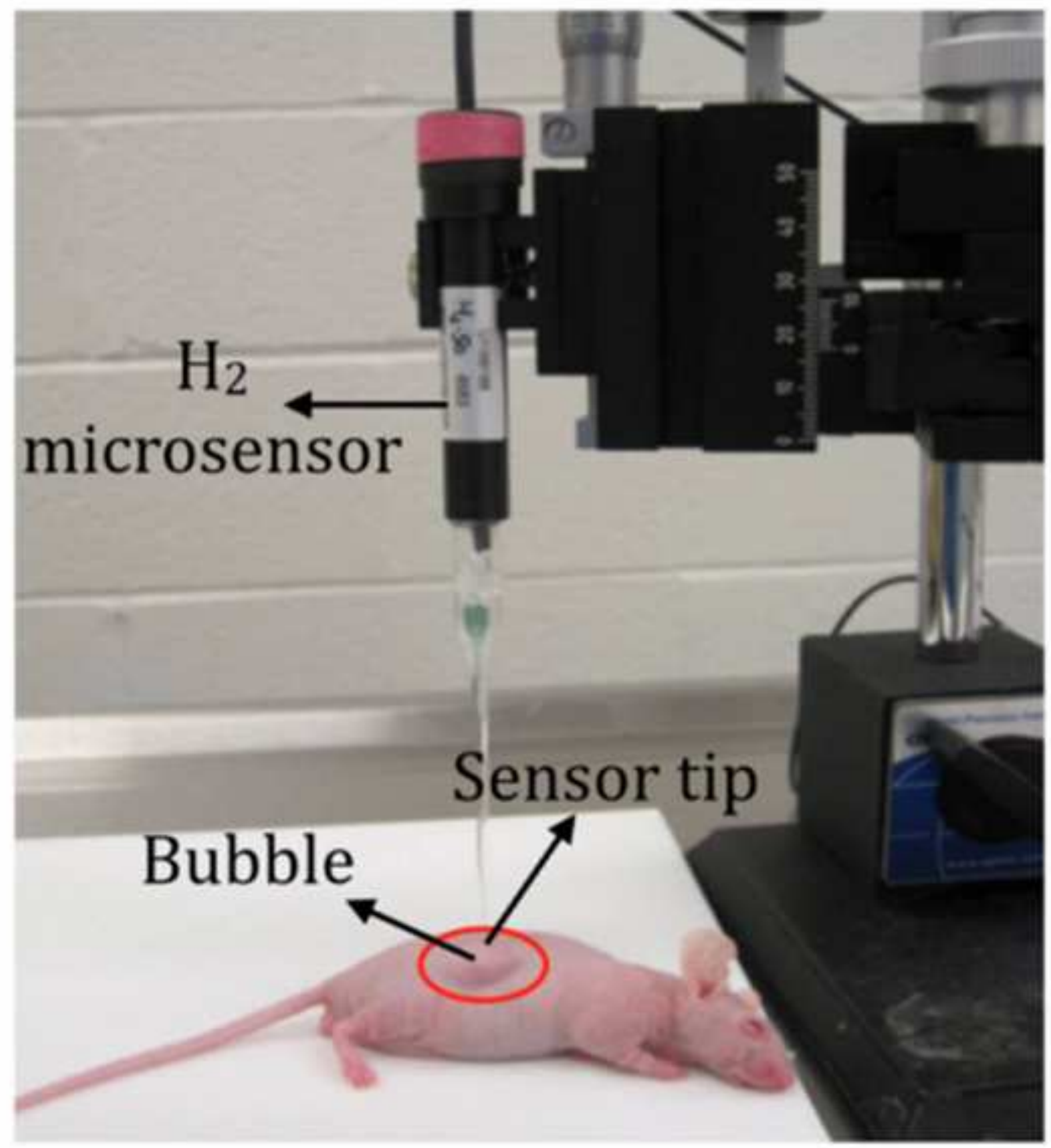



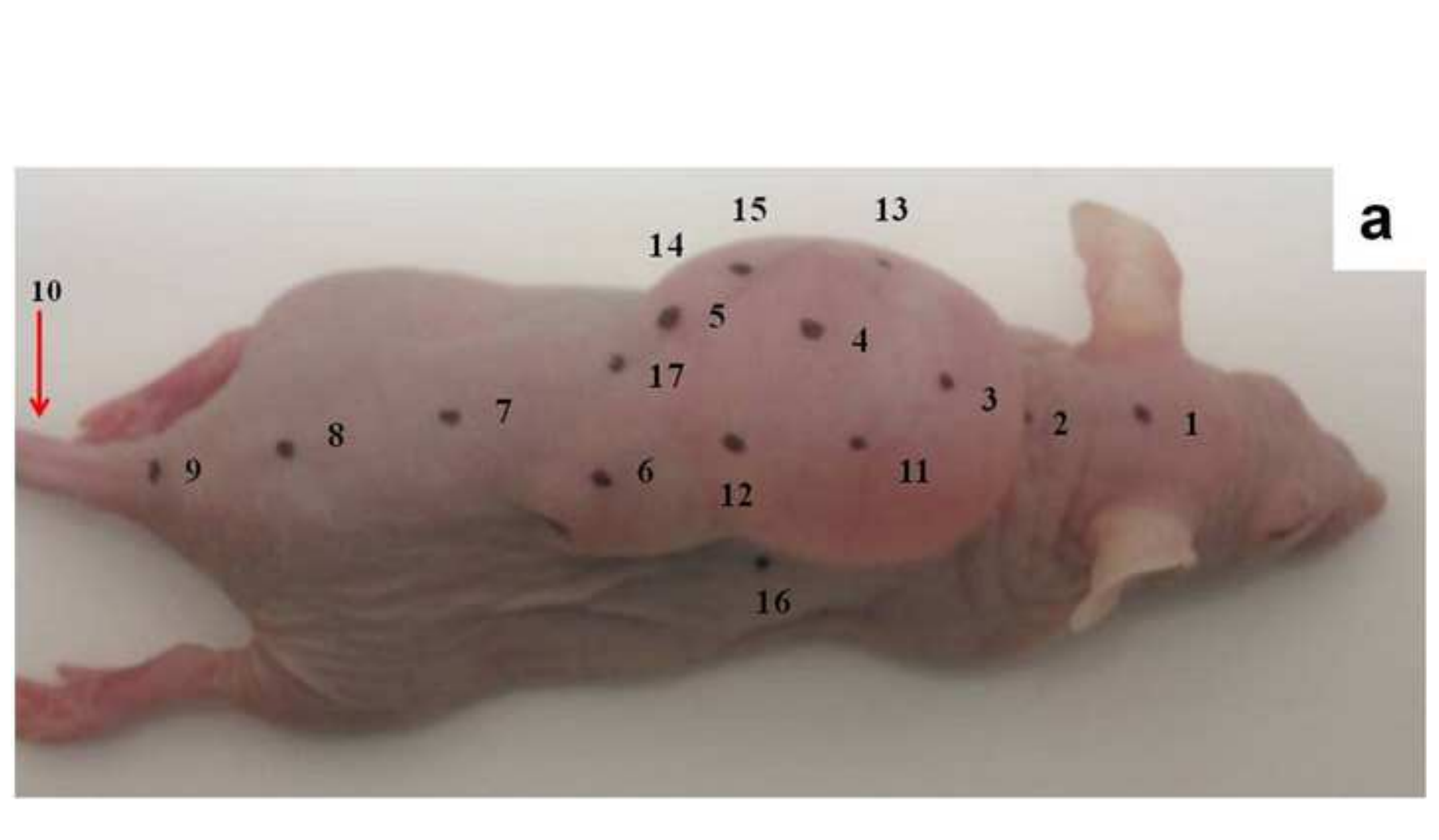


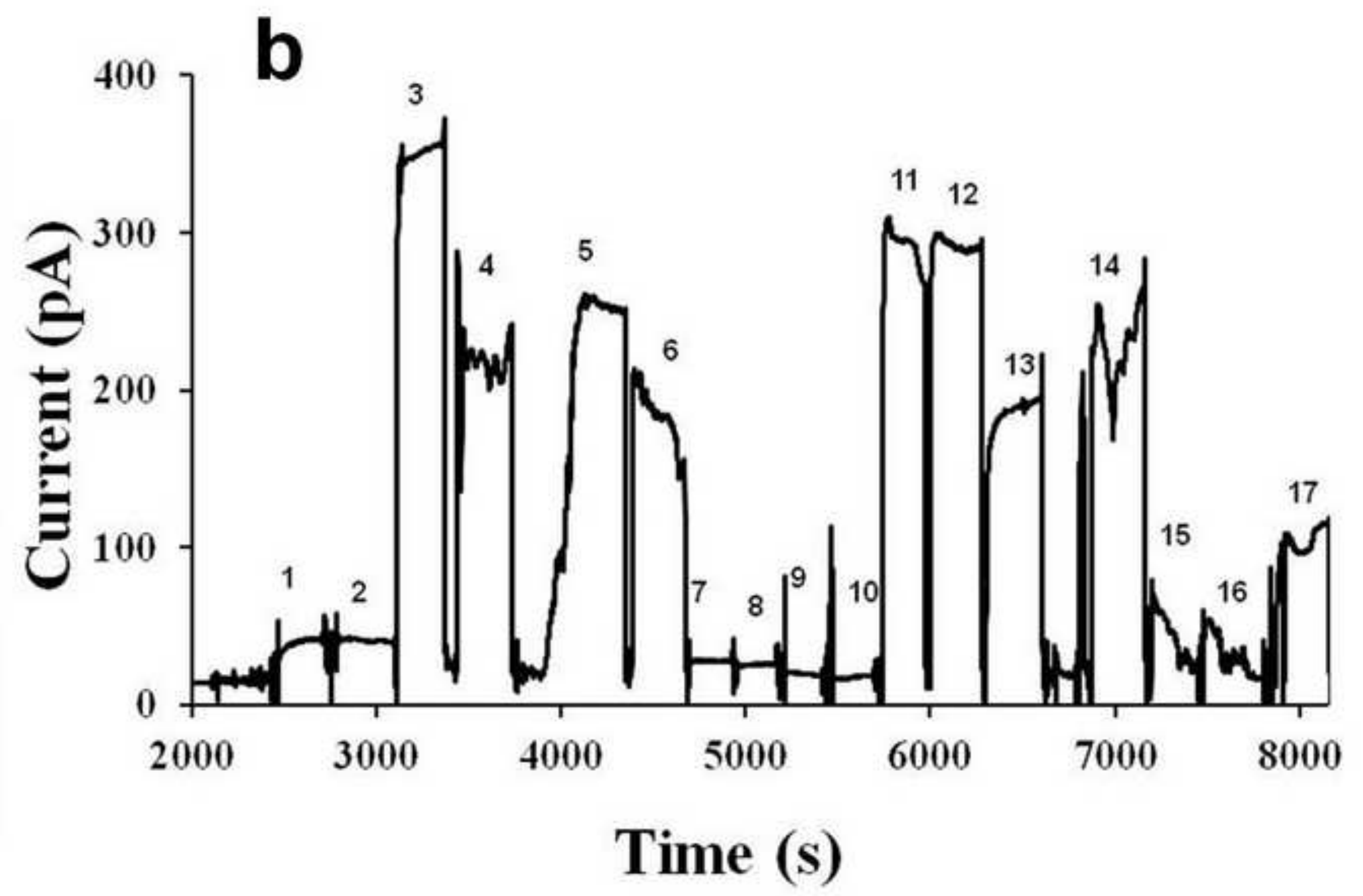




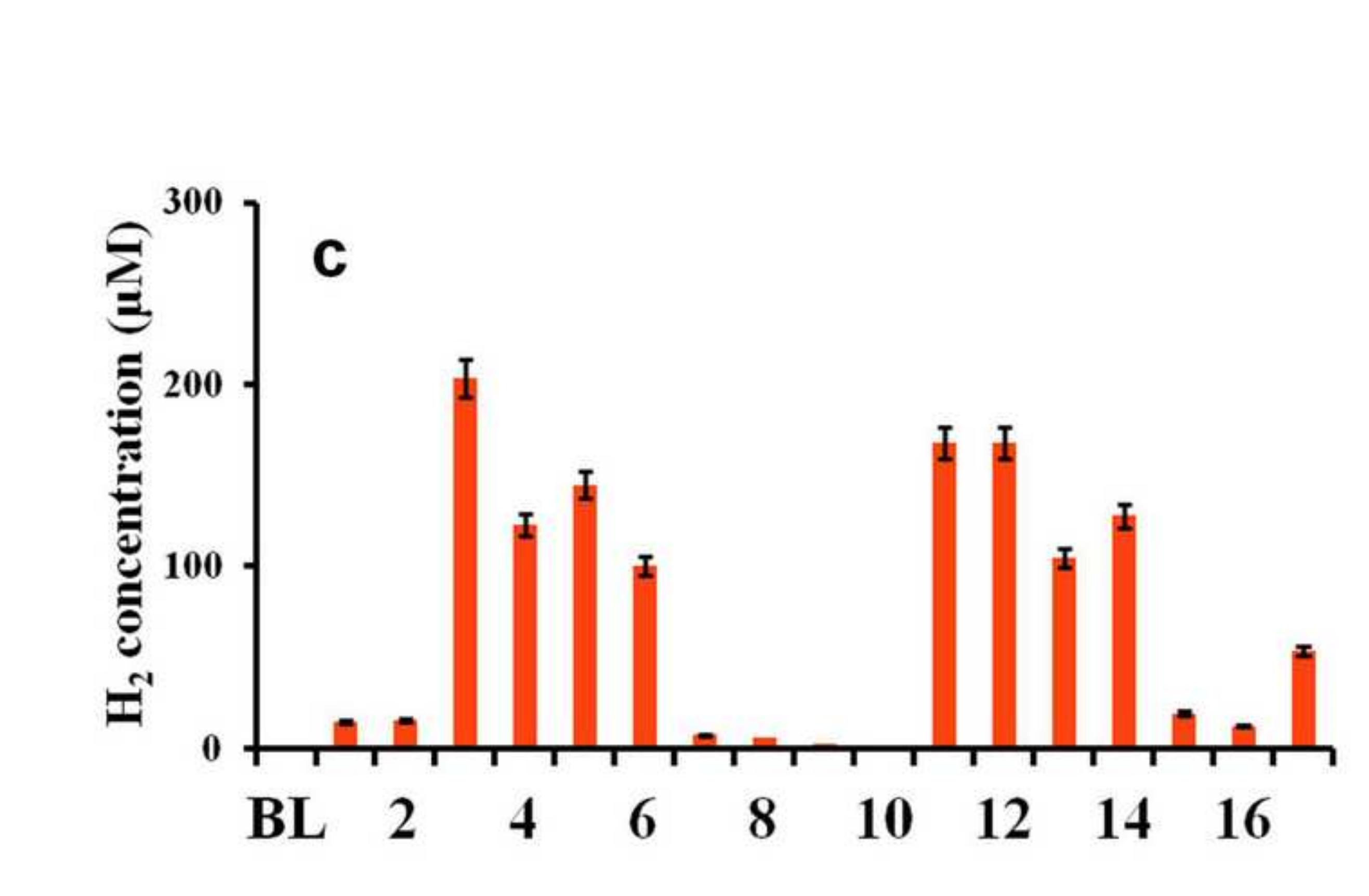

.

.

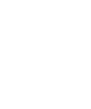

列

(
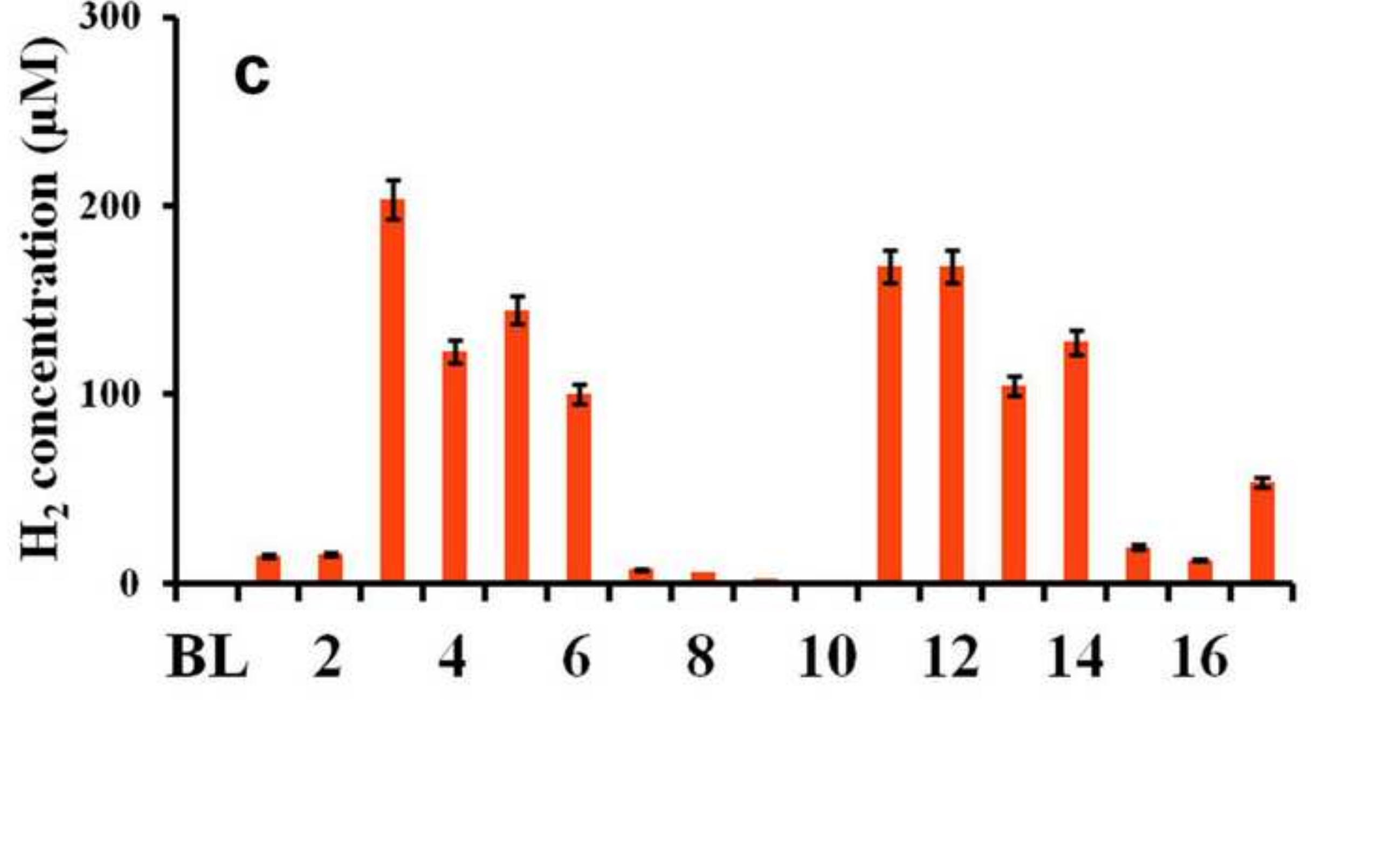


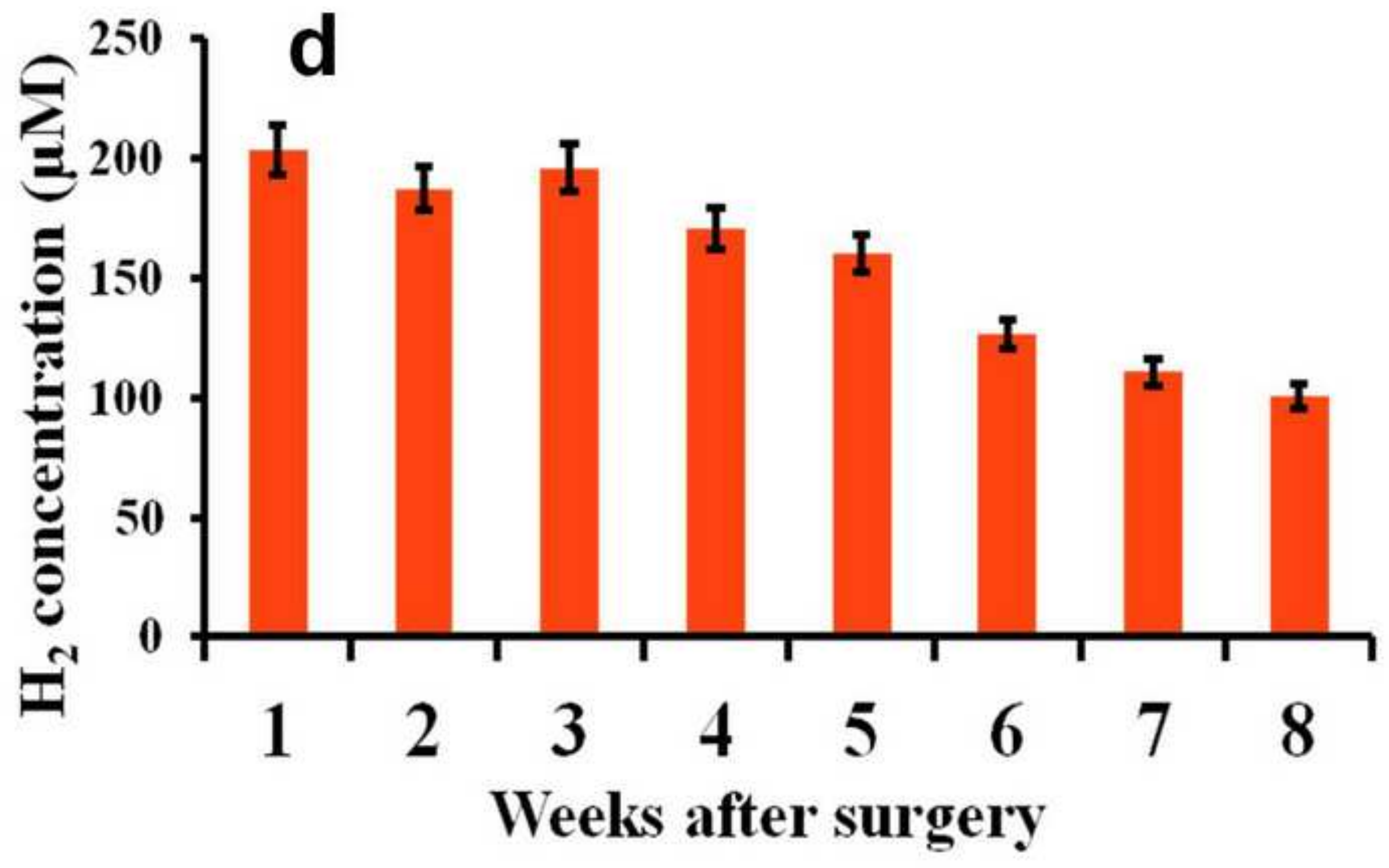


a

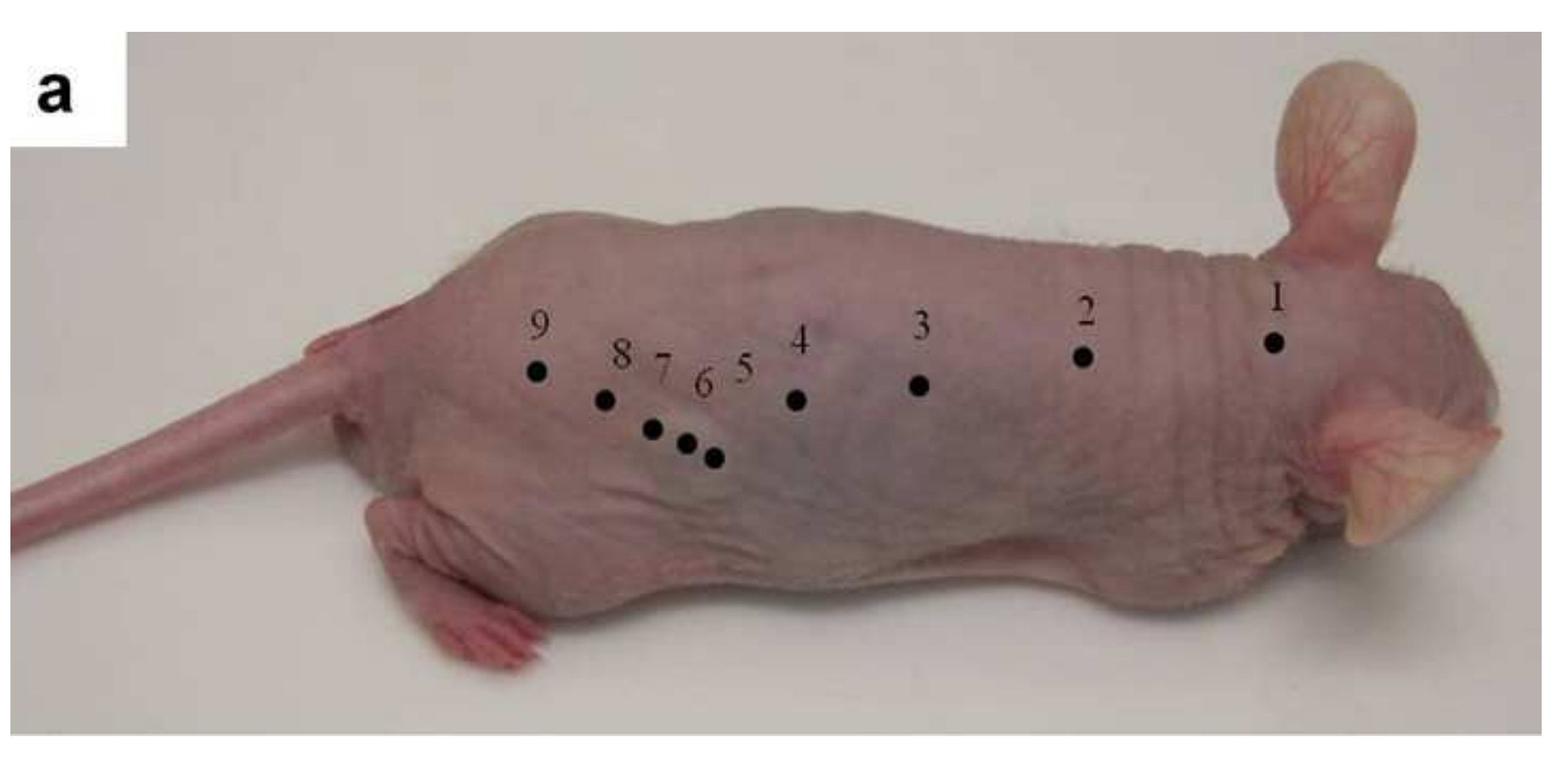

\section{Figure 3}

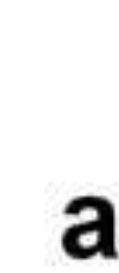

a

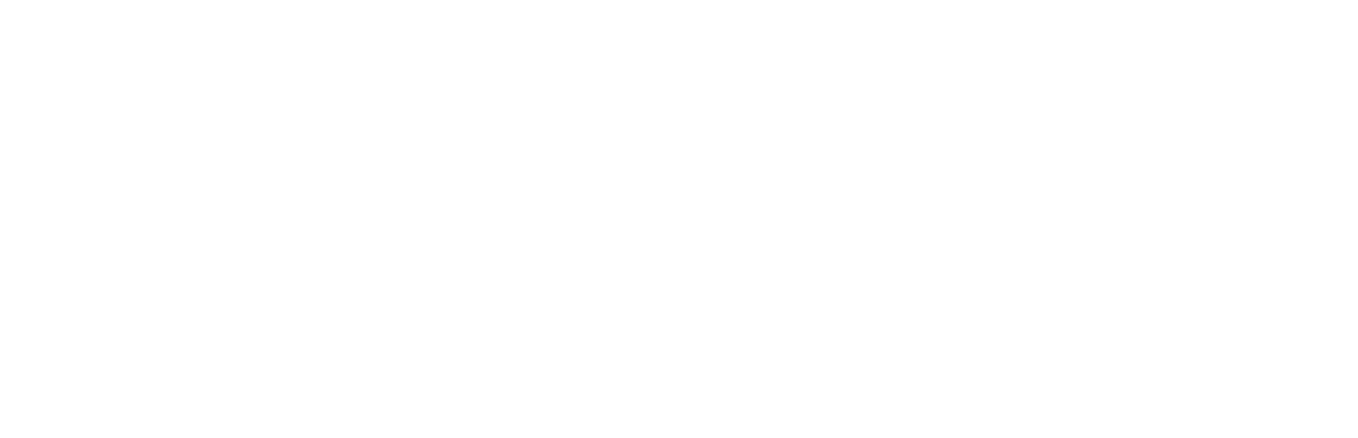

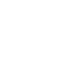




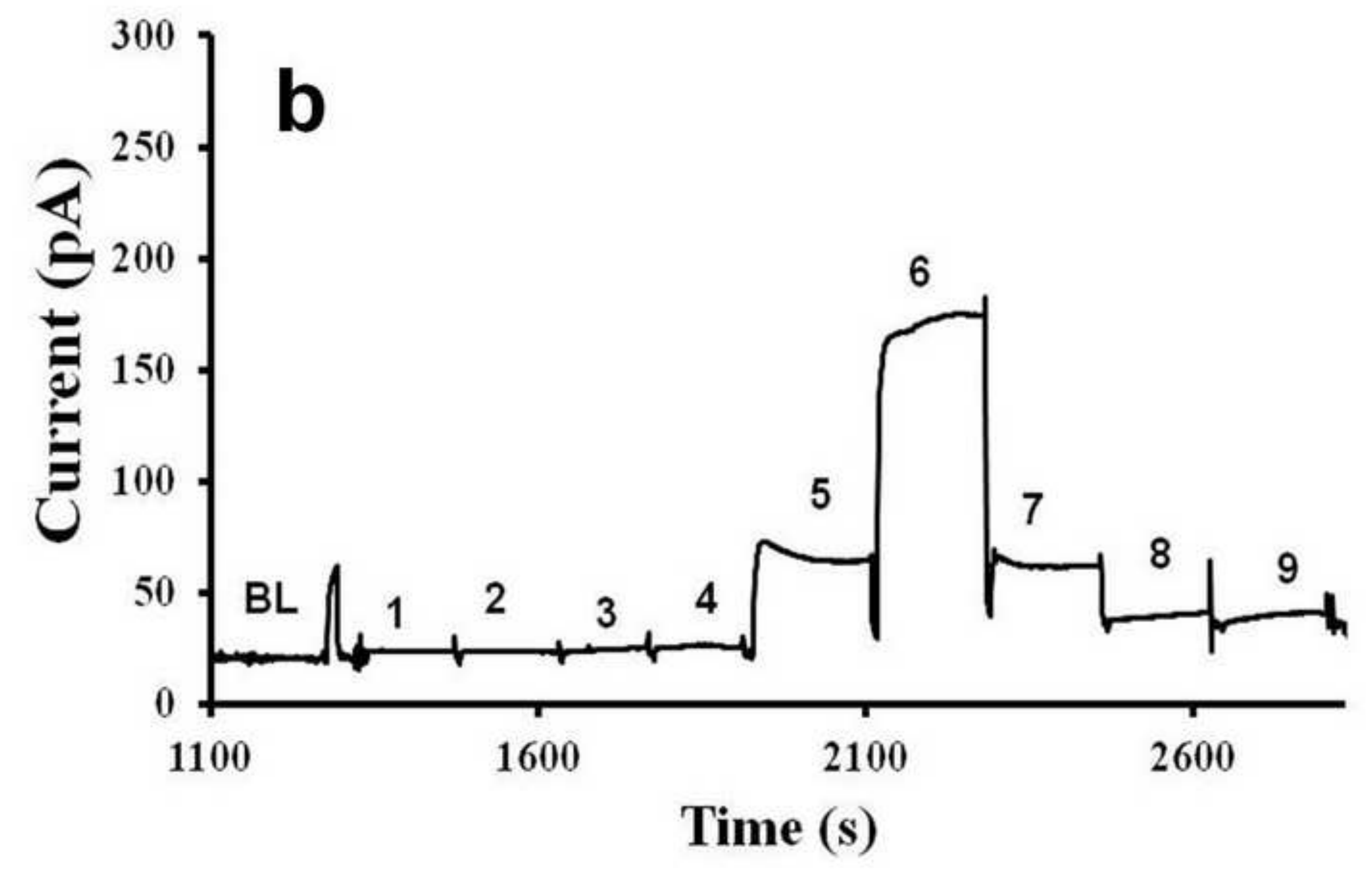




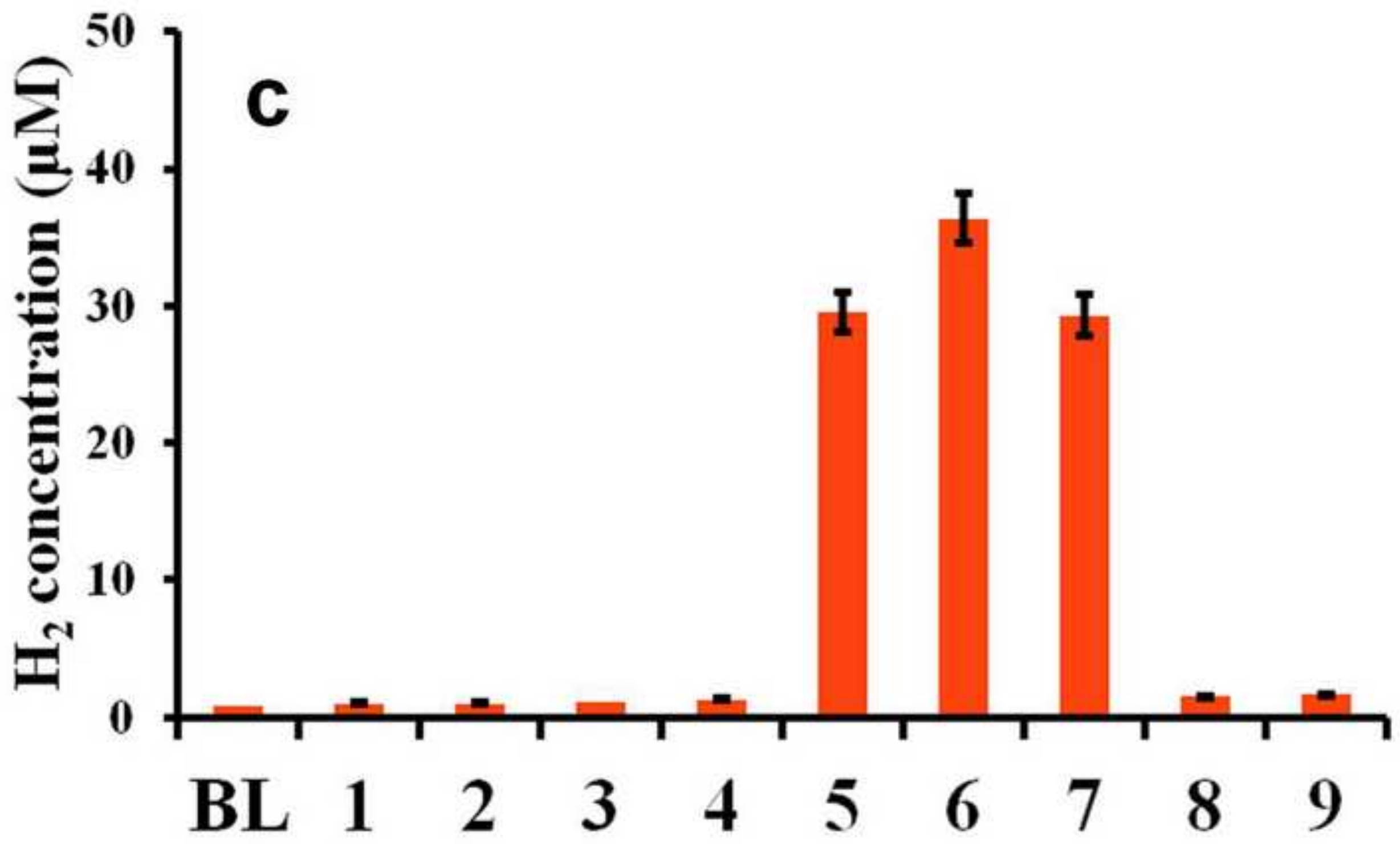




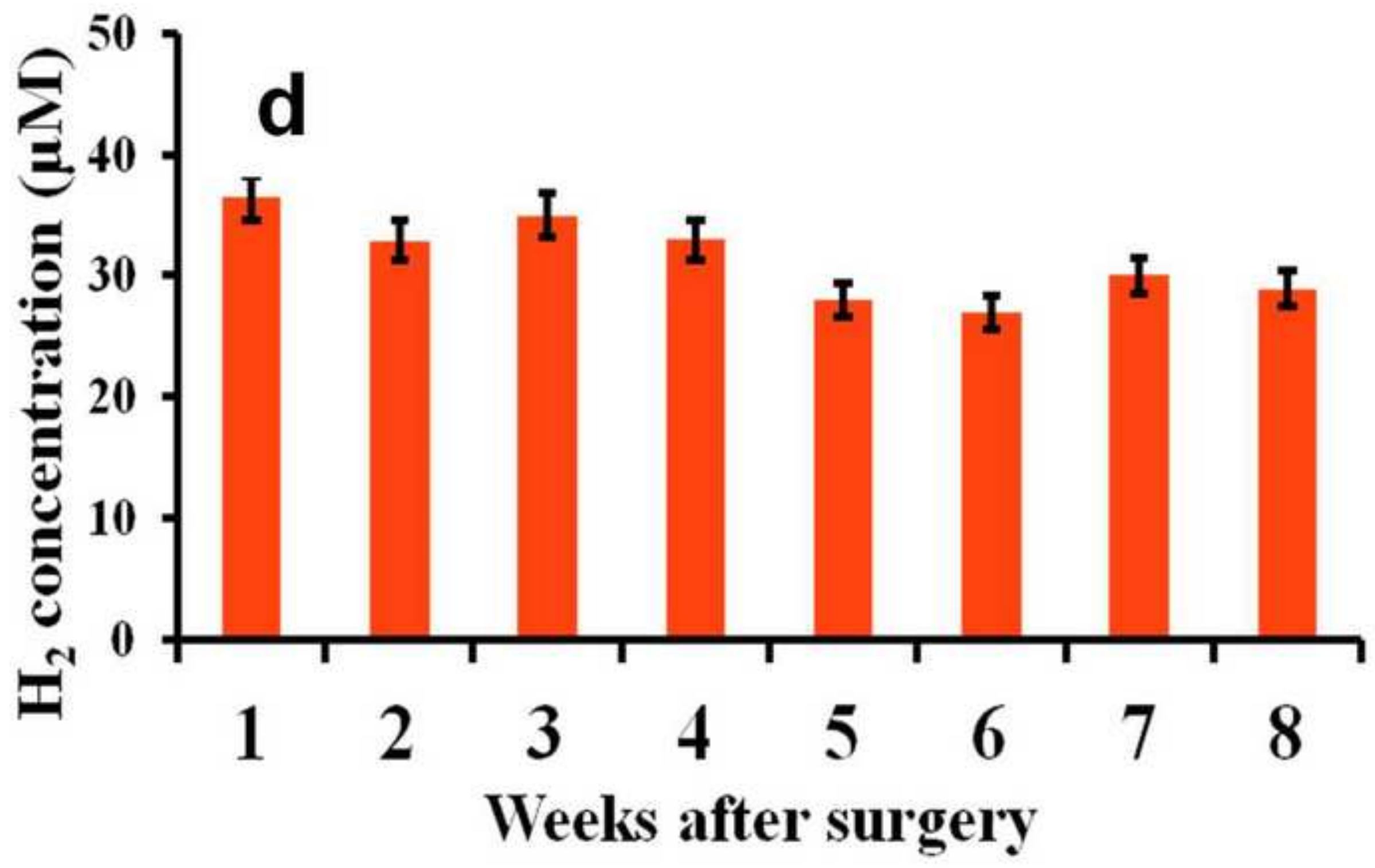




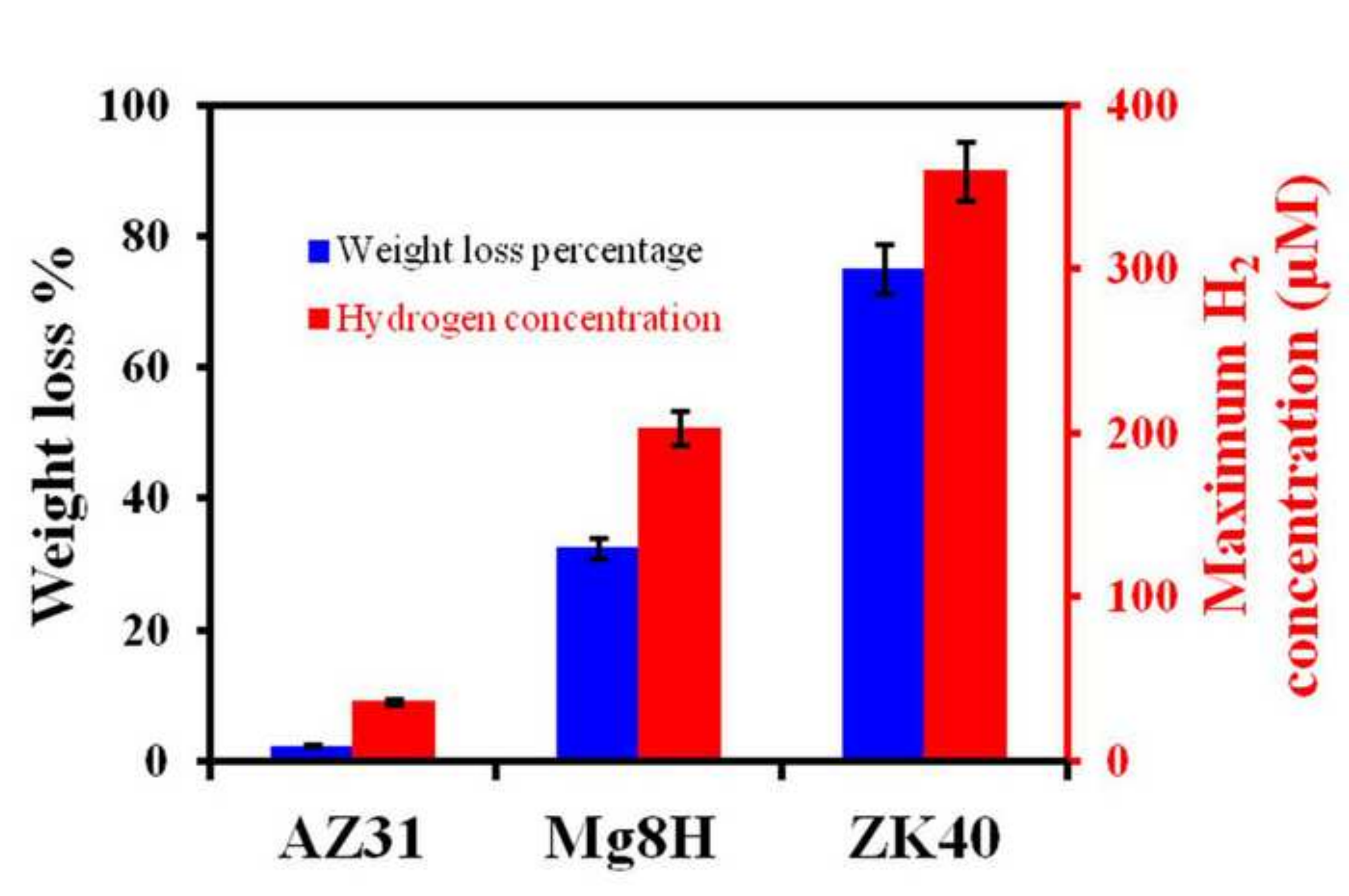




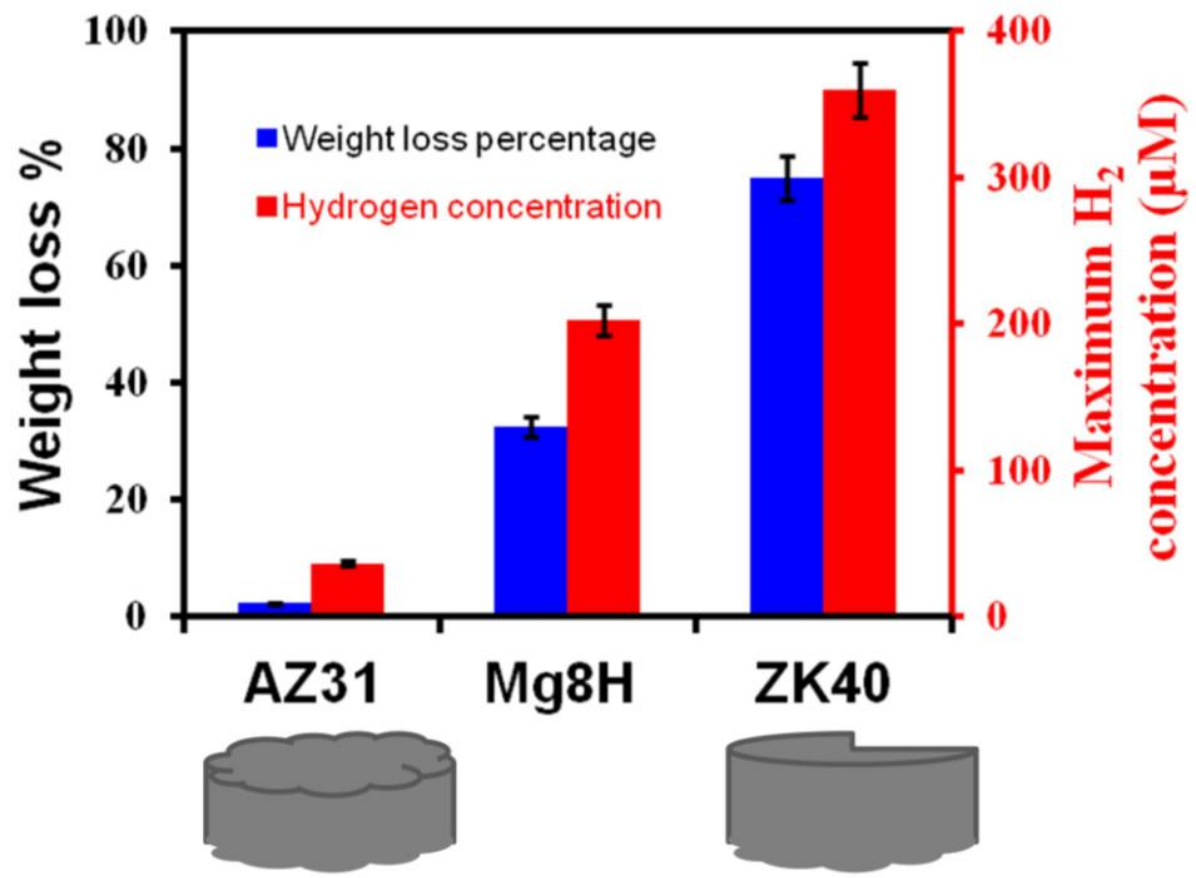

Slow corrosion

Fast corrosion 